\title{
Aerodynamical CFD Study of a non-lethal 12-gauge fin-stabilized projectile
}

\author{
$\checkmark$. de BRIEY \\ I. Ndindabahizi, B.G. MARINUS, Prof M. PIRLOT
}

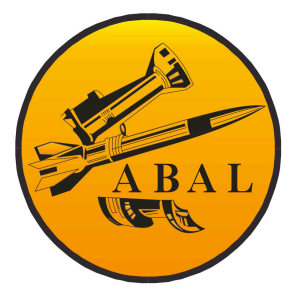

\section{iCONTEXT}

The trajectory model for a subsonic fin-stabilized projectile at low angle of attack is typically a point-mass model (PMM). The disadvantage of this approach is the lack of prediction on the precision and the attitude of the projectile when hitting the target, because of a possible instability. The consideration of other forces and moments acting on the projectile in flight is an instructive step in the field of non-lethal ammunition trajectories.

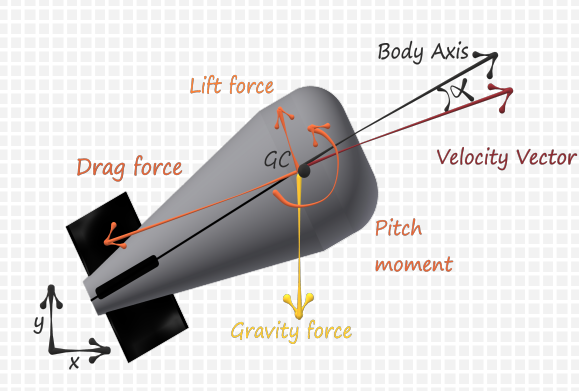

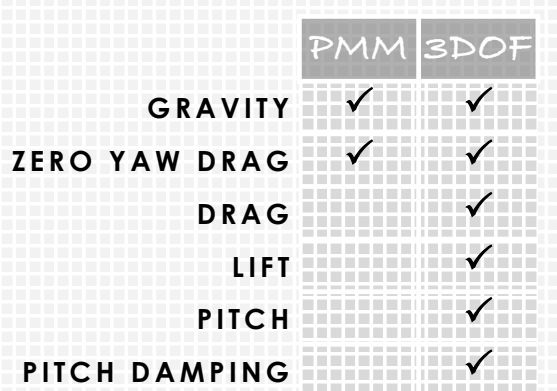

"Gfins" - Config

\section{IIEXPERIMENTAL VALIDATION}

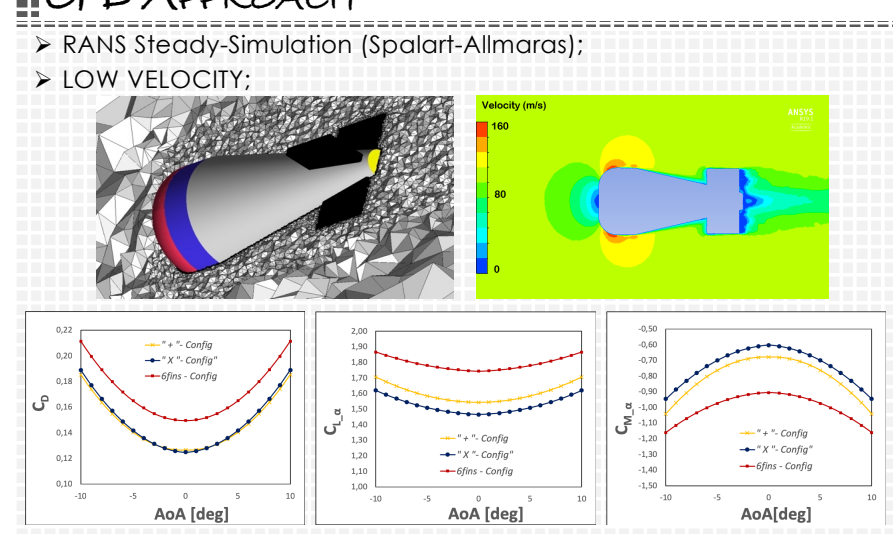

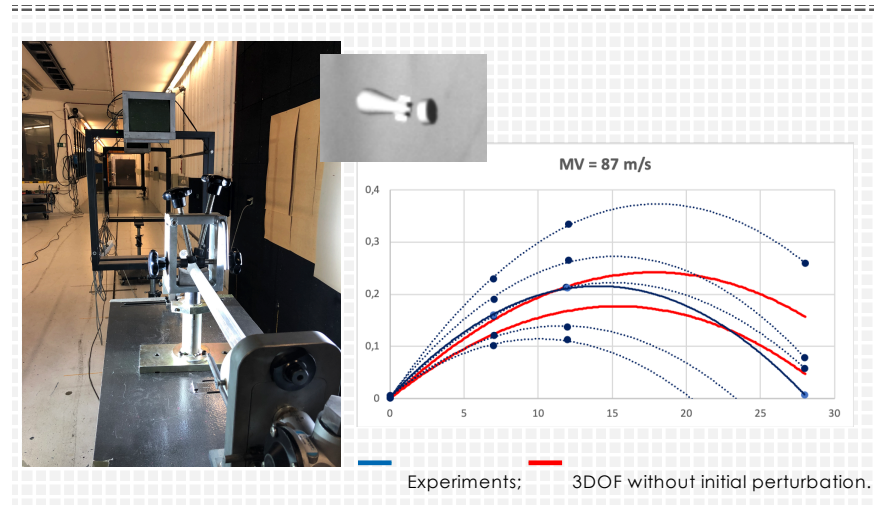

\section{iitrajectories COMPARISON}

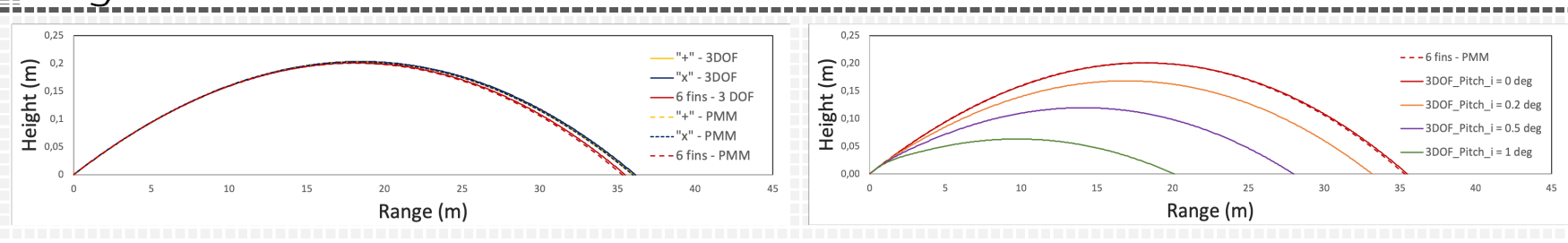

\section{DISCUSSION}

For relatively flat and short-range trajectories, even simple CFD steady methods do not yield a significant improvement in the trajectory prediction given by the PMM provided the projectile exits the barrel under controlled ideal conditions. However, the implementation of a 3DOF is required to account for any pitch angle at the muzzle. An unsteady methodology to compute the pitch damping coefficient in function of the angle of attack becomes really interesting in the design process, in order to limit the destabilization to possible disruptions related to the application (like the separation of the sabot) and in that way to guarantee the right position of the projectile at impact.

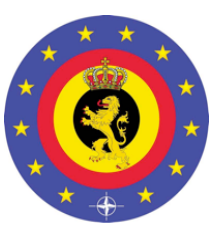

